\title{
A rare case of recurrent urinary obstruction and acute renal failure from cystitis cystica et glandularis
}

\author{
Justin X.G. Zhu, MD; Manal Y. Gabril, MD, ${ }^{* \xi}$ Alp Sener; MD, PhD, FRCSC ${ }^{\dagger \xi}$
}

*Department of Pathology, London Health Sciences Centre, London, ON; †Departments of Surgery \& Microbiology and Immunology, London Health Sciences Centre, London, ON; §Schulich School of Medicine and Dentistry, University of Western Ontario, London, ON

Cite as: Can Urol Assoc J 2012;6(2):e72-74. hittp://dx.doi.org/10.5489/cuaj.11033

\section{Abstract}

We report a rare case of recurrent florid cystitis cystica et glandularis (CCEG), common type, causing obstruction of the left ureterovesicle junction (UVJ) leading to renal colic and hydronephrosis. A 43-year-old man was admitted with renal colic, left UVJ obstruction, left hydronephrosis and azotemia. Cystoscopy showed a $>4$-cm bladder lesion compressing the left UVJ. Transurethral resection of the bladder tumour (TURBT) was performed and pathology revealed the lesion as CCEG. Two months later, the CCEG recurred and caused left UVJ obstruction a second time, requiring TURBT.

\section{Background}

Cystitis cystica et glandularis (CCEG) is a benign proliferative lesion of the bladder mucosa. ${ }^{1}$ Cystitis cystica occurs when von Brunn's nests grow into the lamina propria forming cysts, while cystitis glandularis describes the metaplastic change into goblet cells. ${ }^{1}$ It is believed that CCEG is due to chronic irritation to the bladder epithelium, and do not usually cause symptoms. ${ }^{1-4}$ However, few reported cases exist indicating that CCEG may obstruct the ureteral openings and cause hydronephrosis. ${ }^{3-5}$ We report a rare case of CCEG where the mass caused obstruction and further complication by acute azotemia which required resection. The CCEG recurred within 3 months after the initial resection. To date, we believe this is the first published case of recurrent CCEG leading to hydronephrosis and azotemia.

\section{Case report}

A 43-year-old male presented to the emergency room (ER) with a 3-day history of left flank pain lasting several hours at a time and associated with nausea. He was afebrile and hypertensive (blood pressure 173/82 $\mathrm{mmHg}$ ). He had no previous history of gross hematuria, kidney stones, trauma or chronic/recurrent urinary tract infections. He was otherwise healthy with a known umbilical and left inguinal hernia, both of which were reducible on examination. The initial assessment revealed a completely normal exam with no costovertebral angle tenderness. Social history revealed that he was a body builder who took creatine supplements daily and smoked 2 to 3 cigarettes per day for the past 5 years.

An urgent ultrasound revealed a bladder mass in the trigone (Fig. 1a), with left hydroureter (Fig. 1b) and left hydronephrosis (Fig. 1c). The left ureteric jet could not be visualized on ultrasound. The patient then underwent a noncontrast computed tomography scan of the abdomen and pelvis which revealed no renal or ureteric calculi to account for the hydroureter. Urinalysis was negative for nitrites or leukocytes; urine cytology later came back negative for malignancy. Blood work was normal with the exception of a high creatinine of $231 \mu \mathrm{mol} / \mathrm{L}$ (baseline $109 \mu \mathrm{mol} / \mathrm{L}$ in 2005) with a blood urea nitrogen (BUN)/Cr ratio of 37.7, indicating acute azotemia.

Given that the patient's pain had resolved and that his serum creatinine had declined to $206 \mu \mathrm{mol} / \mathrm{L}$ after fluid resuscitation, he was discharged with urgent urology follow-up. Three days later, the patient presented back to the ER with ongoing flank pain and was taken to the operating room for transurethral resection of the bladder tumour (TURBT). Cystoscopy revealed a large mass arising from the bladder neck, extending along the base and covering the left ureteric orifice such that it was not visible. The right ureteric orifice was lateral and golf-hole in appearance. The tumour was over $4 \mathrm{~cm}$ in size and did not have the characteristic appearance of papillary urothelial carcinoma and appeared more solid in nature. The mass was resected in its entirety, down to the base and area fulgurated. Serum creatinine soon stabilized at $106 \mu \mathrm{mol} / \mathrm{L}$ and the patient was discharge in stable condition, indicating that ureterovesicle junction (UVJ) obstruction was the primary cause for the acute azotemia. It is still unclear why the patient went into 


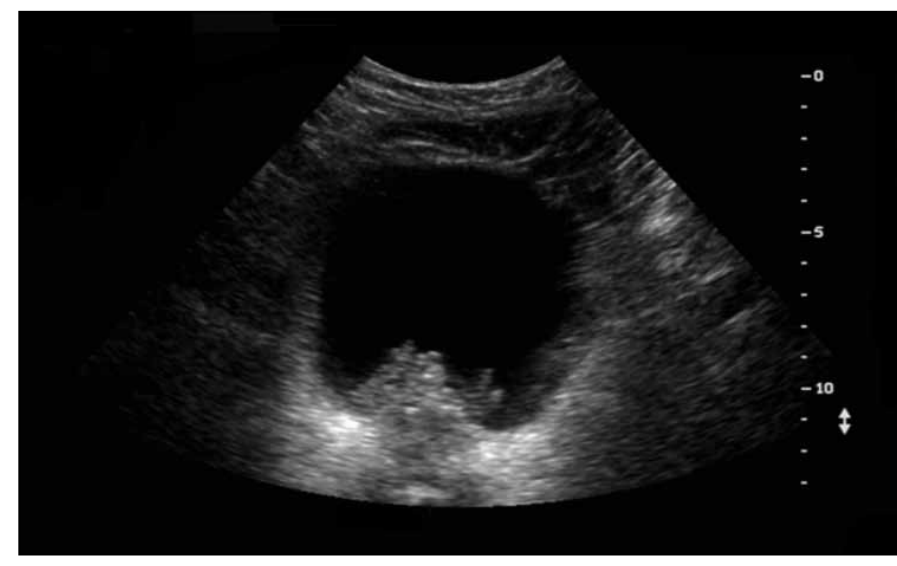

Fig. 1a. Bladder ultrasound showing protruding mass lesion.

acute renal failure with obstruction of one renal unit. Review of the hospital chart did not reveal the use of nephrotoxic medications. It is possible, however, that the sheer mass effect of the lesion, which traversed the entire bladder base, may have also led to a functional obstruction of the contralateral ureteric drainage.

\section{Pathological examination and diagnosis}

Transurethral resection to the bladder lesion was done to obtain a definitive diagnosis. Microscopic examination of 5.1 grams of bladder tissue showed intact urothelial epithelium with underlying edematous lamina propria. Florid CCEG, common type, is identified within lamina propria. The lesion is composed of many glands lined by columnar or cuboidal cells and surrounded focally by urothelial cells. There is no cytological atypia within the lining of the glands noted. There is no evidence of intestinal metaplasia or mucin production. Furthermore, there was no evidence of dysplasia, carcinoma in situ or papillary urothelial carcinoma (Fig. 2, Fig. 3).

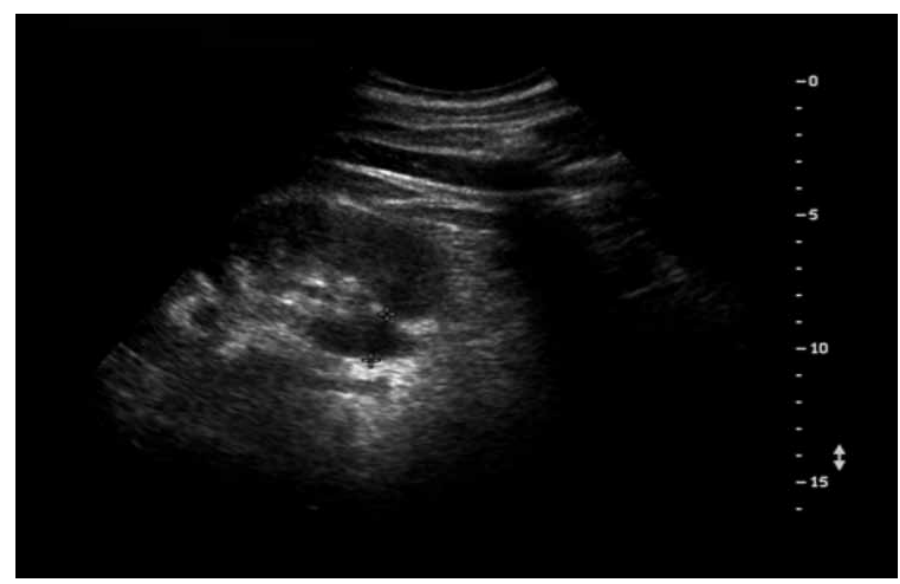

Fig. 1c. Left renal ultrasound showing hydronephrosis and proximal hydroureter.

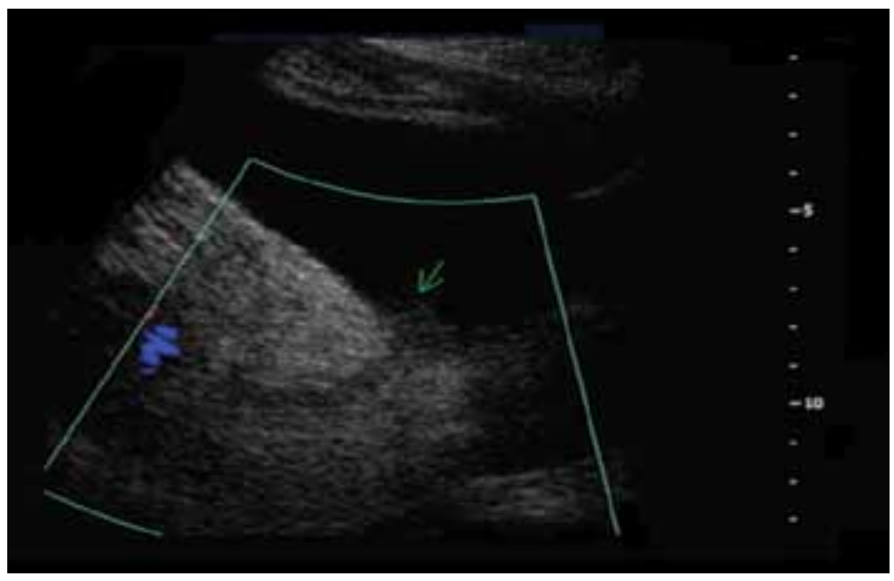

Fig. 1b. Left ureteric ultrasound showing hydroureter down to ureterovesicle junction with no evidence of a ureteric jet.

The results of the first biopsy was discussed with the patient, a 3-month post-TURBT cystoscopy revealed a recurrence of the mass, albeit to a lesser extent, in the same region. The microscopic examination of the bladder tissue of the recurrent lesion showed morphological features in comparison to the first biopsy. Serum creatinine had once again risen to $132 \mu \mathrm{mol} / \mathrm{L}$, so a repeat TURBT was undertaken which revealed similar findings as the first operation.

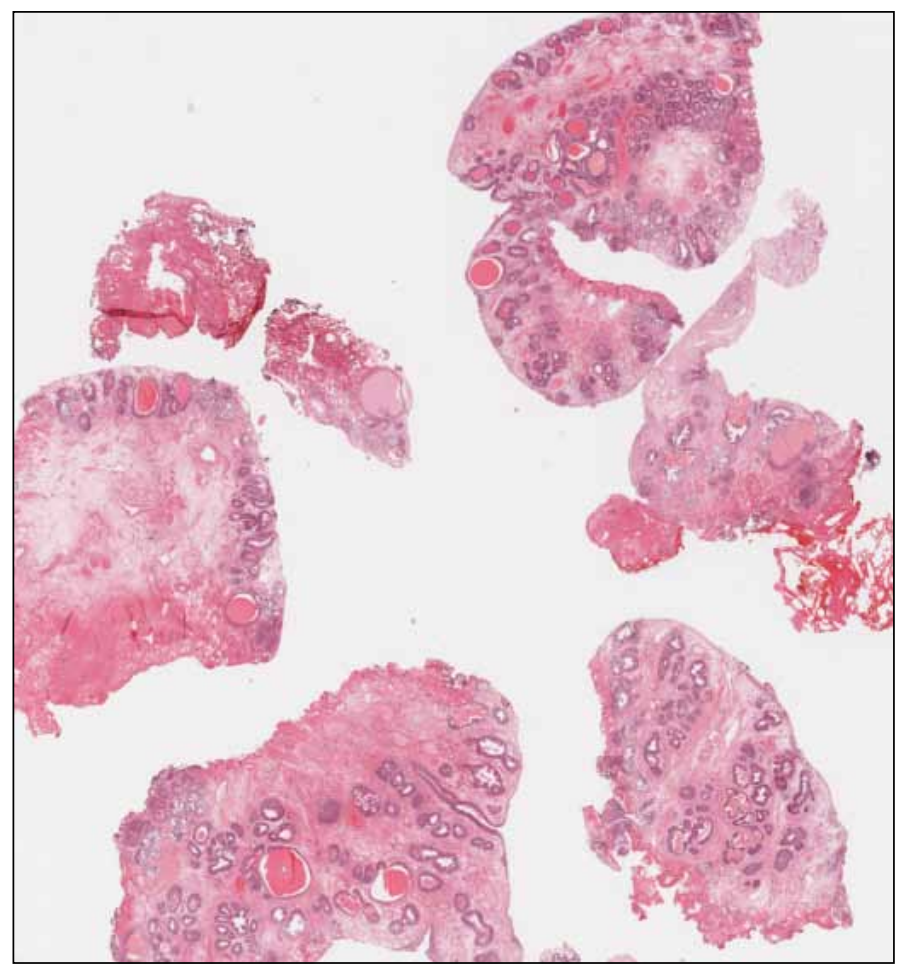

Fig. 2. Lower magnification $(2 x)$ of the transurethral resection of the bladder tumour tissue showing fragments of bladder tissue with cystitis cystica et glandularis, common type: many glands in the lamina propria lined by columnar or cuboidal cells. The urothelial surface is negative for dysplasia or malignancy. 


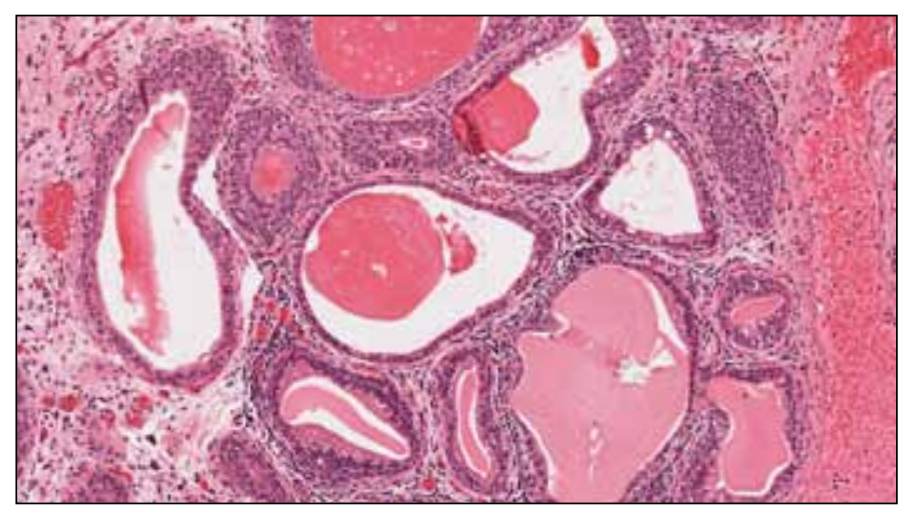

Fig. 3. Higher magnification $\times 20$ : The lining is composed of columnar epithelial cells and focally surrounded by urothelial cells. No cytological atypia is noted. There is no evidence of intestinal metaplasia or mucin production.

\section{Discussion}

CCEG is a benign inflammation of the bladder, characterized by von Brunn's nests that grow into the lamina propria forming cysts and/or metaplastically changing into goblet cells. ${ }^{1}$ Although a common incidental finding in many bladder investigations, CCEG is usually asymptomatic. ${ }^{4}$ There have been previous documented cases of CCEG causing obstruction, reminding us of a rare but potentially important cause for obstruction..$^{3-5}$ We believe this is the first reported case of recurrent CCEG causing obstruction of the UVJ leading to hydronephrosis and acute azotemia.

The etiology to CCEG is unknown, but it is postulated to be related to chronic irritation and inflammation to the bladder mucosa. ${ }^{3,6}$ Many factors have been associated with CCEG, for example, recurrent urinary tract infections, chronic bladder outlet obstruction, neurogenic bladder and recurrent bladder tumours. ${ }^{2,7}$ CCEG is a benign metaplastic lesion of the bladder that needs to be definitively diagnosed pathologically. Other pathological differential diagnoses of this lesion include intestinal metaplasia, adenocarcinoma and nested variant of urothelial carcinoma, which shows small crowded nests with infiltrative base. ${ }^{7,8}$

The treatment of CCEG is usually achieved by treating the underlying cause, however, surgical treatment may be indicated in symptomatic patients, such as in our case. ${ }^{3}$ In recurrent cases, one should treat with a high index of suspicion and continue to monitor the area with surveillance cystoscopy and routine urinary cytology.

\section{Conclusion}

We report a recurrent case of cystitis cystica et glandularis, common type. Normally benign and asymptomatic, CCEG was found to be obstructing the left ureteric orifice, leading to progressive hydronephrosis of the left kidney with ensuing acute azotemia. Despite adequate resection, the lesion recurred within 3 months and required repeat TURBT. The etiology of CCEG in this case is still unclear, although it is commonly related to chronic irritation. While commonly thought of as a consequence to obstruction, CCEG caused acute azotemia in addition to urinary obstruction in our case. We believe this is the first reported case with such specifications.

Competing interests: None declared.

This paper has been peer-reviewed.

\section{References}

1. Rau AR, Kini H, Pai RR. (2009). Morphological evaluation of cystitis glandularis. Indian J Pathol Microbiol 2009;52:203-5. http://dx.doi.org/10.4103/0377-4929.48918

2. Parker C. Cystitis Cystica and Glandularis: A Study of 40 Cases. Proc R Soc Med 1970;63:239-42.

3. Nariculam J, Patel A, Murphy D, et al. (2007). Cystitis Cystica Causing Bilateral Ureteric Obstruction. The Internet Journal of Urology 2007;4(2). http://www.ispub.com/journal/the_internet_journal_of_ urology/volume_4_number_2/article/cystitis_cystica_causing_bilateral_ureteric_obstruction.html. Accessed March 13, 2012.

4. Semins MJ, Schoenberg MP. A case of florid cystitis glandularis. Nat Clin Pract Urol 2007;4:341-5. http://dx.doi.org/10.1038/ncpuro0814

5. Miglani U, Sinha T, Gupta SK, et al. Rare etiology of obstructive urophathy: pelvic lipomatosis. Urol Int 2010;84:239-41. http://dx.doi.org/10.1159/000277606

6. Shigehara K, Miyagi T, Nakashima T, et al. Cystitis glandularis forming a timorous lesion in the urinary bladder: A rare appearance of disease. Indian J Urol 2008;24:558-60. http://dx.doi.org/10.4103/09701591.44268

7. Smith AK, Hansel DE, Jones IS. Role of Cystitis Cystica et Glandularis and Intestinal Metaplasia in Development of Bladder Carcinoma. Urology 2008;71:915-8. http://dx.doi.org/10.1016/i.uroogy.2007.11.079

8. Volmar KE, Chan TY, De Marzo AM, et al. Florid von Brunn nests mimicking urothelial carcinoma: a morphologic and immunohistochemical comparison to the nested variant of urothelial carcinoma. Am J Surg Pathol 2003;27:1243-52. http://dx.doi.org/10.1097/00000478-200309000-00008

Correspondence: Dr. Alp Sener, Departments of Surgery \& Microbiology and Immunology, London Health Sciences Centre, 339 Windermere Rd, P.O. Box 5339, London, ON N6A 5A5; fax: 519 663-3858; alp.sener@|hsc.on.ca 